multifactorial influences amongst which improvements in current levels of clinical care may actually have a minor role.

\section{P133 GUIDELINE ADHERENT THERAPY AND REDUCED MORTALITY AND LENGTH OF STAY IN ADULTS HOSPITALISED WITH EXACERBATIONS OF COPD.}

${ }^{1} \mathrm{PM}$ Short, ${ }^{1} \mathrm{PA}$ Williamson, ${ }^{2} \mathrm{~A}$ Singanayagam , ${ }^{3} \mathrm{~A}$ Akram, ${ }^{1} \mathrm{JD}$ Chalmers, 'S Schembri; ${ }^{1}$ Tayside Respiratory Research Group, University of Dundee, Ninewells Hospital, Dundee, United Kingdom; ${ }^{2}$ Chest and Allergy Department, St. Mary's Hospital, London, United Kingdom; ${ }^{3}$ Royal Infirmary of Edinburgh, Edinburgh, United Kingdom

\subsection{6/thoraxjnl-2013-204457.283}

Introduction Acute exacerbations of COPD (AECOPD) frequently cause hospitalisation and death in COPD patients. The Global Initiative for Chronic Obstructive Lung Disease (GOLD) issued recent guidelines for the treatment of COPD including that of exacerbations. GOLD guidance included the use of corticosteroids, bronchodilators, controlled oxygen therapy and appropriate use of antibiotics and non-invasive ventilation (NIV). We present an analysis of a prospective cohort of patients hospitalised with AECOPD evaluating whether compliance with GOLD COPD guidelines was associated with improved survival and reduced length of hospital stay (LoS)

Methods A prospective observational cohort study of patients admitted with AECOPD. Patients were $>40$ years of age, with spirometrically confirmed COPD and admitted to one of 12 UK centres between 2009-2012. We evaluated adherence to guidelines on steroid, antibiotic, bronchodilator, oxygen and NIV use. Patients' care was classified by the number of adherent guideline domains creating 5 groups; i.e. those whose care was compliant with only one guideline to those who care was compliant with all. The primary outcome was 30 day in-hospital mortality, LoS was the secondary outcome. Cox proportional hazards regression was used to calculate adjusted hazard ratios (HR) for analyses of guideline adherence.

Results 1343 patients were included in our study. There were no patients whose treatment was not compliant with any guidelines while the management of 349 individuals was fully complaint. Inpatient mortality was $6.2 \%$. Patients whose care was compliant with one or 2 guidelines were used as the reference group for mortality analysis as only 13 patients had care compliant with a single domain. The HR for patients compliant in 3,4 and 5 guideline domains were $0.81(0.41-1.61) \mathrm{p}=0.4,0.58(0.30-$ 1.13) $\mathrm{p}=0.1$, and $0.40(0.19-0.87) \mathrm{p}=0.01$ respectively. Figure 1 shows the relationship between survival and guideline adherence. Concordance with individual guideline domains was not associated with improved mortality. The median LoS decreased from 11 (interquartile range $6-15$ ) in those who care had only one compliance to $5(2-10)$ in fully compliant care $(\mathrm{p}<0.0001)$. Conclusion Management of AECOPD that was fully concordant with GOLD guidelines was associated with significantly improved mortality and shorter hospital stays.

\section{P134 THE FACTORS ASSOCIATED WITH READMISSION OF PATIENTS WITH EXACERBATION OF CHRONIC OBSTRUCTIVE PULMONARY DISEASE (COPD) WITHIN 30 DAYS ARE LARGELY OUT OF CONTROL OF HEALTHCARE PROFESSIONALS AND THE TRUST-THE DEPARTMENT OF HEALTH'S (DOH) CASE FOR PENALISING TRUSTS FOR 30 DAY READMISSION IS WEAK AND UNJUSTIFIABLE}

S Kadri, RK Sinha; Yeovil District Hospital NHS Foundation Trust, Yeovil, Somerset, United Kingdom

\subsection{6/thoraxjnl-2013-204457.284}

Introduction and Objective Early readmission of patients with COPD is responsible for significant healthcare costs. To minimise this, DoH has proposed financial penalties to Trusts for readmissions within 30 days of discharge ${ }^{1}$. Previous studies have questioned this proposal's justification ${ }^{2}$. We conducted this study to examine this issue in our Trust.

Methods List of patients with primary diagnosis of COPD readmitted within 30 days of discharge in 2011 was obtained from clinical coding department and was further scrutinised to identify patients in whom this diagnosis was correct. Available notes were reviewed and data was collected using a locally designed pro-forma.

Results From initial list of 361 episodes, 47 patients were readmitted over 53 episodes of which 25 were truly for exacerbation of COPD. Patient's characteristics are described in Table. Readmission occurred even if patients were on maximum/optimum treatment $(96 \%)$ and had respiratory input (84\%). Only 3 episodes (12\%) required ventilator support (invasive/ non-invasive) that could not have been managed outside hospital. The average length of stay was 8.12 days.

Conclusions and Discussion The best medical care during initial admission does not reduce readmission. Factors associated with readmission are largely unmodifiable by medical intervention and beyond control of healthcare professionals and Trusts. Admission avoidance schemes are not available widely; and may be answer to the problem by reducing rate of admission through various supportive and non-medical measures made available in the community. Incentive for lower readmission rates rather than penalty for higher readmission may encourage Trusts to invest in admission avoidance services. The bed cost alone would be $£ 53,592$ for 22 avoidable admissions with hospital stay of 8.12 days@£300/day. Non-payment for readmissions would amount to a loss of $£ 87,079$ on minimum tariff of $£ 1643 /$ patient. $53 \%$ of this would have been for wrongly coded patients; and may be a matter of interest for managers.

\section{REFERENCES}

1. "The Operating framework for the NHS in England 2011-12"-by Department of Health - page 52, paragraph-5.33.

2. J Hare et al. 30-Day COPD readmissions relate to disease severity and demographic factors rather than simply organisation and delivery of hospital care. Thorax 2011;66: Suppl 4 A107-A108.

\begin{tabular}{|c|c|c|c|c|}
\hline $\begin{array}{l}\text { Total COPD } \\
\text { admission } \\
\text { episodes } \\
\text { in } 2011\end{array}$ & $\begin{array}{l}\text { Number } \\
\text { of } \\
\text { patients }\end{array}$ & $\begin{array}{l}\text { Total } \\
\text { episodes of } \\
\text { readmission }\end{array}$ & $\begin{array}{l}\text { Readmission } \\
\text { episodes for } \\
\text { COPD Exacerbation }\end{array}$ & $\begin{array}{l}\text { Readmission } \\
\text { for } \\
\text { non-COPD } \\
\text { Diagnosis }\end{array}$ \\
\hline 361 & $47(14.68 \%)$ & 53 & $\begin{array}{l}25 \text { out of } 53(47 \%) \\
(7 \% \text { of original } 361)\end{array}$ & $\begin{array}{l}28 \text { out of } \\
53(53 \%)\end{array}$ \\
\hline \multicolumn{5}{|c|}{ Characteristics of readmitted patients } \\
\hline \multicolumn{3}{|c|}{ - Age > 70 years (mean 72.3 ) } & \multicolumn{2}{|c|}{ Stable state hypercapnoea (43\%) } \\
\hline \multicolumn{3}{|c|}{$\begin{array}{l}\text { - Admitted at least once in the } \\
\text { previous year }(64 \%)\end{array}$} & \multicolumn{2}{|c|}{ - Nebuliser dependant (64\%) } \\
\hline \multicolumn{3}{|c|}{ - Living alone $(76 \%)$} & \multicolumn{2}{|l|}{ - FEV1 <50 \% (65\%) } \\
\hline \multicolumn{3}{|c|}{ - Associated co-morbidities (72\%) } & \multicolumn{2}{|c|}{ - Functional status MRC 3 or above $(76 \%)$} \\
\hline
\end{tabular}

